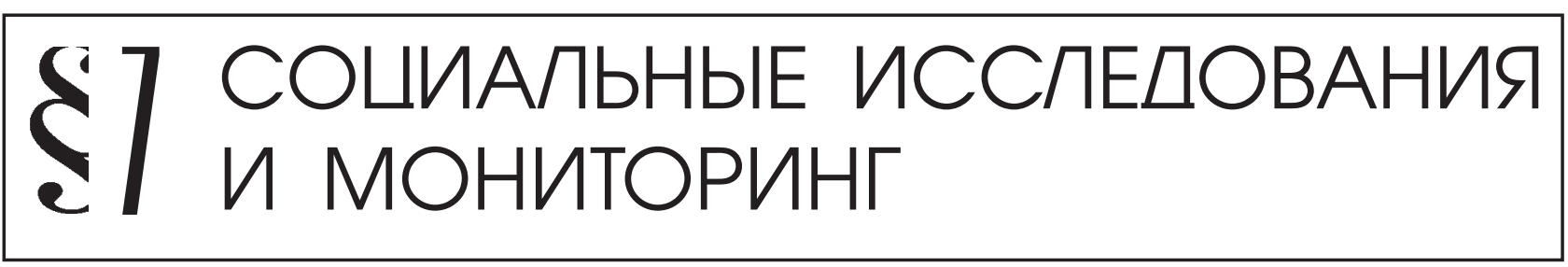

Е.А. Попов

\title{
МЕЖДИСЦИПЛИНАРНЫЙ ОПЫТ ГУМАНИТАРНОГО ЗНАНИЯ И СОВРЕМЕННОЙ СОЦИОЛОГИЧЕСКОЙ НАУКИ
}

\begin{abstract}
Аннотация: Статья посвящена актуальной проблеме, которая не может быть обойдена вниманием ни одной современной отраслью знания - проблеме интеграции наук. Точки зрения исследователей на этот счет разделились - некоторые отстаивают принци самодостаточности различных областей соииально-гуманитарного знания, другие указывают на необходимость тесного взаимодействия научных сфер. В предлагаемой статье приводится анализ различных положительных и негативных сторон такого междисииплинарного взаимодействия. Особо подчеркивается роль сочиологии в процессах интегращии знаний. На примере данной научной отрасли рассматривается методологический вектор взаимодействия философии и соииологии, сочиологии и в целом социогуманитарного знания. Результаты, представленные в статье, имеют значение для определения объектно-предметного пространства разных наук, а также для выработки задач по сохранению приниипов научности, которые могут быть подвержены трансформации в ходе таких междисциплинарных отношений.
\end{abstract}

Ключевые слова: Социология, общество, наука, междисииплинарность, методология, развитие, философия, соииум, политизация, соџиальность

$\mathrm{P}$ азвитие наук приводит к обострению ситуации, связанной с определением их статуса в условиях междисциплинарного взаимодействия различных отраслей знания. Объективность такого положения наук вызвана их включенностью в масштабные проекты современности, а следовательно, необходимостью соответствовать требованиям стремительного поиска новой информации.

Современное социогуманитарное знание стало всерьез уступать позиции знанию естественнонаучному. Такое положение вещей прежде всего свидетельствует о многих характерных чертах эпохи. Во-первых, для рубежа столетий кризис мировоззрения и сопутствующая ему масштабная переоценка ценностей - дело совершенно обычное; свои хрестоматии резких скачков и переходов от старого к новому в ценностно-смысловой системе координат создавали и демонстрировали все без исключения рубежные времена и в особенности, конечно, к. XIX - н. XX вв., а теперь и к. XX н. XXI вв. В последнем случае речь идет не просто о рубеже веков, но и о сломе тысячелетий, что само по себе многократно увеличивает и обостряет противостояние различных мировоззренческих позиций, онто- логических установок, социальных феноменов и процессов. Но главное, как нам кажется, заключается в еще более открытом сопротивлении личностного общественному. И подоплека здесь не только и не столько политическая или идеологическая, а скорее гносеологическая - человеку становится более родным не то знание, которое получено от жизненного опыта или мудрости, а знание, добытое строгим методом и прикладным усилием. Такое твердое знание постулируется естественными науками, и оно отнимает у исследователя его чувственность и эмоции, загоняет его в пространство осязаемого факта и рациональной действительности. Во-вторых, в границах слома эпох пока никак не может уместиться какая-либо значимая парадигма, которая бы направляла развитие знаний в определенное русло. Несколько лет подряд на финишной линии ушедшего XX-ого века такой парадигмой был постмодернизм, заявивший такие принципы, от которых содрогнулась гуманитарная наука - потеря человека, выхолощенность культуры, политизация и юридизация индивидуальной и коллективной жизнедеятельности человека. Постмодернизм занял умы многих исследователей и по сути привел их к тому, 


\section{Политика и общество 4 (100) • 2013}

что они стали «отказываться» от социальных смыслов бытия, но к сожалению, не обратили свои взоры и к человеку. Неотвратимость кризиса научности - вот о чем сказал всему миру постмодернизм. После этого кто только не писал и не размышлял о том ступоре, в котором оказались все гуманитарные науки. Но что примечательно - для всех них (исследователей) важной находкой, способной вывести из кризиса многие и многие научные области и сферы, оказался так называемый междисциплинарный уровень познания окружающей реальности. Тот самый, который быстро вывел из состояния методологической растерянности те научные отрасли, которые некогда были самодостаточными и никак не реагирующими на всплеск модного увлечения межнаучностью.

Особняком среди этих обстоятельств стоит рост конъюнктурности науки - уровень ее развития перестал измеряться открытиями и интересными находками исследователей, но зато приобрел зависимость от той материальной выгоды, которую то или иное знание способно принести. Погоня за «научными» денежными средствами стала главным методом современного знания. И на этом фоне такой счет складывается в пользу естественных наук - их технологии способны принести реальную прибыль, гуманитарным наукам же остается отстаивать важнейший постулат - нести культуру в массы. Этот некогда застывший в переходе времен лозунг получает свою вторую жизнь в наши дни. Но в силу того, что сама культура переживает непростые годы, а ее многочисленные интерпретации подчас становятся едва ли не самоцелью некоторых областей знания из «гуманитаристики», то все более выраженным для науки становится прикладное начало, апеллирующее к строгому методу и технологии. При этом, как полагает Л.Д. Гудков, «в сегодняшней социологии отсутствует то, что М. Вебер выразительно характеризовал как чувство многомерности ситуаций или положений, человеческих мотиваций. Многоплановость смысловых образований сегодня сводится социологами к «общественному», к институтам» ${ }^{1}$. Социологию, как видим, критикуют за многое. И неудержимый выпад против социологии не в том, конечно, что она собственно увлечена «общественным», а скоpeе все же в ее недостаточном внимании к человеку, к

\footnotetext{
${ }^{1}$ Гудков Л.Д. Социология культуры: научно-аналитический обзор тематического номера «Кельнского журнала по социологии и социальной психологии» // Культурология: Дайджест. М., 2012. № 1 (60). С. 52.
}

личному. В этом убеждены и те, кто склонны попенять социологии на ее отрыв от философии и философствования, а значит, и на утерю социологией онтологической прозорливости и «отношения к личности» ${ }^{2}$, и те, кто резонно в наши дни задаются вопросом: существует ли сегодня наука социология ${ }^{3}$. К чести самой социологической науки, она не раз убедительно демонстрировала свою самодостаточность в системе знаний, не покушаясь на модную междисциплинарность, завладевшую методологическим пространством многих современных научных сфер. Может быть, социологию следовало укорить лишь в том, что она сравнительно легко вычленяет все новые и новые предметные области для себя (как в социологии досуга, социологии терроризма и экстремизма и т.д.), становясь, таким образом, меркой мира, однако важно отметить социология не заблуждается относительно некоторых таких миров, важнейших для общества, культуры, человека. Следует, видимо, признать - междисциплинарная тенденция развития многих современных наук крадет у них не только свой собственный взгляд на реальность и вещи, который нередко приходилось отстаивать в течение десятилетий на дискуссионных площадках и в настоящих идейных сражениях, но и заметно меняет вектор оценки тех или иных явлений и процессов. На примере социологии можно убедительно показать - прикладное начало нередко подминает под себя онтологический ракурс в изучении социальных феноменов, а к некоторым областям духовной жизни социология не может подступиться, потому что в их исследовании не всегда «срабатывает» метод, на чувственные же оценки социология не падка и философствования старается избегать. Это касается, например, сфер искусства, мышления, ментальности и др.

Социологии, пожалуй, действительно недостает философствования для более уверенного интерпретирования социальных фактов и явлений. С точки зрения А.С. Ахиезера, «сконцентрированный в культуре накопленный опыт превращается в программу воспроизводства, фокусируется в личности, испытывает органическую перестройку, перефокусацию, пере-

\footnotetext{
${ }^{2}$ См., например: Алексеева И.Ю. Модели философии // Философские науки. 2012. № 9; Марков Б.В. Образ человека в постантропологическую эпоху // Вопросы философии. 2011. № 2 .

${ }^{3}$ Щербина В.В. Существует ли сегодня наука социология? // Социол. исследования. 2012. № 8 .
} 
осмысление, интерпретацию и т.д.» ${ }^{4}$. По такому пути идет социология - фокусирует внимание на пороговых проблемах, актуальных для стран и народов, переосмысливает диагнозы социальной реальности, выданные наукой и политикой в прошлые времена. Но социолог не может не понимать важность и необходимость взгляда на эти процессы в онтологическом ключе. С другой же стороны, социология в наибольшей степени зависима от прикладного начала, а следовательно, она не может рассчитывать только лишь на философскую рефлексию и ограничивать себя постановкой проблемы. Если рассматривать такое положение вещей сквозь призму извечного и не решенного до сих пор вопроса о взаимоотношении гуманитарного и социального как фундаментальных систем знания о человеке, обществе и культуре, то социология здесь едва ли не единственная наука, которая объединяет и гуманитарное, и социальное в пределах своего объектно-предметного пространства и методологии. Другие сферы познания мира все же более условно соединяют в себе и то и другое, иллюстрируя скорее необходимость и неизбежность такой интеграции, нежели демонстрируя реальность ситуации. Из-за подчеркнутого внимания социологии к общественным проблемам и нередкого оставления человека «в опасности» или «не у дел» социологию, по-видимому, трудно признать областью рефлексии. В.П. Култыгин отмечал, что «под термином рефлексивность социологическая теория подразумевает рост автономного мышления и индивидуалистического творчества» ${ }^{5}$. Тем не менее творчество в социологии скорее состоит в том, чтобы показать умения и навыки ловкого обращения с эмпирическими методами и выкладками результатов прикладного исследования. Процесс этот трудоемкий, как известно, и требующий от исследователя определенной сноровки, но и объекты исследовательского внимания соответственно должны «компенсировать» такие затраты. «Возрастающая сложность мира требует более изощренных методов его изучения. Прямое сопоставление и «суммирование» данных разных дисциплин, которое может способствовать решению прикладных задач, при генерации фундамен-

\footnotetext{
${ }^{4}$ Ахиезер А.С. Об особенностях современного философствования (Взгляд из России) // Вопросы философии. 1998. № 2. C. 6 .

${ }^{5}$ Култысин В.П. Тенденции в европейской социологической теории начала XXI века // Социол. исследования. 2001. № 8. C. 28.
}

тального знания оказывается недостаточным» - отмечают некоторые исследователи ${ }^{6}$ В то же время, как полагает В.А. Ельчанинов в работе «Негативная методология науки», «метод организует и дисциплинирует поиск истины, позволяет в случае правильности экономить силы и время, двигаться к цели наиболее целесообразным и выгодным путем» ${ }^{7}$. Как видим, от выбора метода зависит многое в любом исследовании, а тем более в том, которое без эмпирики выглядит блеклым и манифестным. Поэтому было бы неоправданно ждать от современной социологии резкого подъема интереса к тем областям мира и атрибутам бытия, которые не дадут возможности сэкономить силы, но которые в тоже время для философии стали бы в одночасье приманкой для рефлексии. К примеру, ни у кого не вызывает сомнения то обстоятельство, что социология искусства как отраслевое направление современной социологической науки существует уже давно, но вот вопрос - насколько притягательной эта сфера бытия общества, человека и культуры (искусство) является для исследователя. Риторический вопрос. Разобраться в искусстве нашим современникам совсем не просто, а вот философы не чураются этой высокой области и более того - привносят в ее изучение новые линии анализа.

Для гуманитарной науки уступки в методологических исканиях в сторону междисциплинарности неизбежны, но в то же время не столь безвредны - это, пожалуй, грозит возвратом к разделению всех наук на «традиционалистские» и новаторские или что-то в этом роде; такое положение вещей в свою очередь вполне способно привести к осовремениванию эпохального противостояния теории и практики в науке с явной диспозицией в пользу прикладного осмысления реальности, а для некоторых направлений знания также противостояния гуманитарного и социального начал. При этом науки «традиционалистские», к примеру, будут отстаивать свою методологическую самодостаточность с избирательным подходом ко всяким новациям, вторые, не обращая внимания на возможную утерю своей «индивидуальности», станут бросать на щит любой «идеальный тип» научности. По справедливому замечанию В.Е. Кемерова, когда речь за-

\footnotetext{
${ }^{6}$ Александров Ю.И., Кирдина С.Г. Типы ментальности и институциональные матрицы: мультидисциплинарный подход // Социол. исследования. 2012. № 8.С. 4.

${ }^{7}$ Ельчанинов В.А. Негативная методология науки: монография. Барнаул, 2012. С. 7.
} 


\section{Политика и общество 4 (100) • 2013}

ходит «о влиянии общественных наук друг на друга, - тут возникает тема существенных различий: цена вопроса - научный, институциональный, методологический суверенитет, которым никто поступаться не хочет» ${ }^{8}$. Действительно, всем современным наукам приходится решать для себя, в каком виде они будут подтверждать свою суверенность либо обосновывать исследовательские начинания с чистого листа, сопровождаемые обретением нового научного аппарата и системы методологических установок. В этом смысле примечательной является позиция М.Н. Эпштейна, разобравшего «гуманитарность» что называется по полочкам с целью обнаружить конструктивный потенциал гуманитарных наук: «Критическая сторона гуманитарности - денатурализация и деполитизация человека, разоблачение того, что естественным и общественным наукам представляется твердым, позитивным основанием объективности. Конструктивная сторона гуманитарности - это построение новых знаков, означаемым которых становится сам гуманитарный субъект, не столько открывающий нечто в мире объектов, сколько производящий собственную субъективность методами самоназначения и самообозначения (акценты другим шрифтом расставлены автором цитаты. - E.П.)» ${ }^{9}$. Разоблачение, конечно, не дело науки, но с другой стороны, как иначе достичь равенства начал в отстаивании объективности своего объекта и предмета исследования?

Между тем гуманитарная наука как будто и не спешит сдавать свои позиции, отыскивая вполне удовлетворительные, как нам кажется, но одновременно и эксцентричные варианты совпадения наук «в одном флаконе». Так, например, появилась формула интеллигентности $(\mathrm{I}=[\mathrm{C} \& \mathrm{~V}] \mathrm{kT}$, где I - интеллигентность, $\mathrm{C}$ - интеллектуальная постоянная: образованность и креативность, V - этическая переменная: индивидуальное или субкультурное самоопределение и т. д. ${ }^{10}$, допускающая в принципе возможность какого-либо математизированного «среза» такой сложной категории, которой интеллигентность является в представлениях совершенно разных культурно-исторических

\footnotetext{
${ }^{8}$ Кемеров В.E. Гуманитарное и социальное: от оппозиции к синтезу // Человек. 2011. № 1. С. 5.

9 Эпштейн М.Н. Конструктивный потенциал гуманитарных наук: могут ли они изменять то, что изучают? // Философские науки. 2008. № 12. С. 37.

${ }^{10}$ Соколов А.В. Формула интеллигентности // Вопросы философии. 2005. № 5. С. 64.
}

эпох и носителей культурных ценностей. Примерно в этом же ключе определил «эмпирический концепт личности» В.А. Кутырев, полагая, что он создается в результате вычета телесности и выпадения личности из реальных социальных связей ${ }^{11}$. Такой метод вычитания способен придать любой реальности новые смыслы; исследователю лишь остается принять ту или иную сторону на линии водораздела человека и общества, личности и государства и др. О разработке «индекса охраны человеческого достоинства» заявляют М.А. Краснов и П.М. Краснов ${ }^{12}$. Стремления исследователей придать тому или иному «социогуманитарному» явлению практическое звучание, инструментальный смысл или объективировать - понятное желание. В этой связи должна усиливаться исследовательская позиция социолога; в то же время его задача не допустить искажения социальной реальности как-то совсем уж не согласуется с утверждением о сервильности социологии, ее потребности услужить интересам государства, каких-либо социальных групп или хозяйствующих субъектов: «...социология теперь должна обрести новые формы взаимосвязей с властными и управленческими структурами, с системой образования, хозяйственными и коммерческими структурами, политическими партиями и т.д.» ${ }^{13}$. В то же время особая увлеченность социологии всем социальным и институциональным лишает и самих субъектов научной деятельности, осуществляемой в этом направлении, чувства жизни, которая по меткому выражению А.Ф. Лосева, «есть бурлящая и клокочущая бессмыслица, апофеоз безумия» ${ }^{14}$. Значит ли это, что социолог утрачивает это чувство жизни за констатацией накладывающихся друг на друга как снежный ком фактов и обстоятельств, свидетельствующих о значительной трансформации не только человеческих индивидуальных и коллективных ценностей, но и собственно систем координат, в которых эти ценности пребывают - социальных, политических, правовых и других.

Действительно, на первый взгляд кажется, что социологи излишне выделяют критичные или кризис-

\footnotetext{
${ }^{11}$ Кутырев В.А. От какого наследства мы не отказываемся // Человек. 2005. № 2. С. 11.

${ }^{12}$ Краснов М.А., Краснов П.М. К разработке Индекса охраны человеческого достоинства // Общественные науки и современность. 2011. № 6 .

${ }^{13}$ Москвичев Л.Н. Этапы институционализации российской социологии // Социол. исследования. 2006. № 7. С. 9.

${ }^{14}$ Лосев А.Ф. Страсть к диалектике. М., 1990. С. 27.
} 
ные моменты в окружающей реальности, утверждая нередко крушение важнейших основ бытия. Повидимому, внимание социологов в большей степени занимают именно такие проблемы, эмпирическое исследование которых дает довольно красноречивые и убедительные результаты, поэтому сегодня пользуются вниманием темы социального самочувствия, благополучия, бедности и малообеспеченности, алкоголизма и наркотизации населения и т. д. Но при этом социолог может оставаться безучастным к таким проблемам, изучение которых не сразу способно дать сиюминутные результаты, к тому же их непопулярность вызвана необходимостью вести отсчет измерения именно с некой онтологической «точки», приближая таким образом социологию к философии в нарушение принципа «чистоты» эксперимента. Но социология - не философия. Это с очевидностью, думается, обозначилось в яркой увлеченности социологии именно вопросами социальными, возведением в ранг наивысших ценностей социальности как некой константы современной жизни. Потеря личности для современной социологической науки еще не стала фатальным моментом, но при этом вся социальногуманитарная отрасль знаний утверждает: человек в социальном мире остается на обочине социальной реальности. Не допустить этого - дело и гуманитарных дисциплин, и собственно социологии.

Очевидно, что именно человек, а не социиальность в ее всепроникающем воздействии на мир, должен стать тем пунктом назначения, в котором сходятся интересы разнообразных областей знания. Между тем, как отмечают исследователи, затянувшийся характер негативных социальных процессов привел «к распаду привычных социальных связей, множеству мелких конфликтов внутри человека и при общении с другими членами общества. Переживание личного опыта каждого человека сформировали общую картину общественного неблагополучия (курсив автора цитаты. - E.П.)» ${ }^{15}$. Здесь как будто усматривается укор самому человеку за его неспособность или невозможность что-либо противопоставить жестокой социальной реальности. Проблема, конечно, вечная - человек. К ее осмыслению скрупулезно подходили и физики, и лирики - и «естественники», и гуманитарии. Первые убе-

${ }^{15}$ Александров Ю.И., Кирдина С.Г. Типы ментальности и институциональные матрицы: мультидисциплинарный подход // Социол. исследования. 2012. № 8. С. 101. дительно встраивали человека в систему поведенческих отношений, в свое время взятую за основу в социобиологии, другие в свойственной им манере давали амбивалентную оценку - и позитивную, и негативную - развитию человека, его мировоззрению в эпохи слома ценностей и норм. По мысли В. Беньямина, в XX веке «его (человечества. - E.П.) самоотчуждение достигло той степени, которая позволяет переживать свое собственное уничтожение как эстетическое наслаждение высшего ранга» ${ }^{16}$. Мысли о человеке всегда путались, были то яркими и по-публицистски привлекательными, то невыразительными и малоэффектными; в двадцать первом столетии человек забыт, покинут, а смыслы социального опутывают эту реальность с поразительной завоевательской силой и тщанием. Пожалуй, при таком стечении обстоятельств особая миссия отведена именно социологии. Она в угоду смыслам социальности не может оставить человека одного, но важно понять: чем может подогреваться интерес современной социологии к человеку? По-видимому, двумя вещами: 1) перенесением силы тяжести в объектно-предметном пространстве преимущественно с проблем общественных на проблемы взаимодействия общества, культуры и человека ${ }^{17}$; между тем такое заметное расширение горизонта научности вынуждает социологию постоянно находиться не только в поиске новейших средств для постижения указанных феноменов, но также и в прицеле междисциплинарности; 2) осознанием ответственности за формирование позиции «относительно человека» на рубежах социально-гуманитарных дисциплин. Пожалуй, сегодня пункт об ответственности науки за правду, сказанную о человеке, культуре и обществе, должен быть возведен в разряд основополагающих принципов научности. Правда же о человеке, сказанная наукой, как нам кажется, все более склоняется в одну сторону - показать декаданс современной личности. Об этом заявляют и философы, и социологи, и исследователи других направлений. Но крайнюю позицию ухода социальных наук от человека выразил, как нам представляется, В.Е. Кемеров, отметивший, что «в социальных науках люди,

\footnotetext{
${ }^{16}$ Беньямин В. Произведение искусства в эпоху его технической воспроизводимости. М., 1996. С. 65.

${ }^{17}$ См. об этом: Попов Е.A. Диверсификация социогуманитарного знания: смыслы социального и апология суперсоциального // Социол. исследования. 2012. № 11. С. 3-4.
} 


\section{Политика и общество 4 (100) • 2013}

по сути, не рассматриваются в их особенном бытии, а их сила и способности учитываются лишь в абстрактных формах и измерениях» ${ }^{18}$.

На утрату важнейшими научными областями человекоцентричных ориентиров указывает и междисциплинарность как критерий научности в современных условиях развития знаний; он открывает перспективы обмена методом и методологией, парадигмами и целями, но одновременно с этим отводит личности место на вторых ролях, поскольку предметные сферы наук составляют их частный интерес. Междисциплинарность, конечно же, объективна она свидетельствует о полноте дыхания наук, не желающих в чем-то себя ограничивать, стремящихся к получению нового знания или новой информации за счет смежных связей. Вопрос при этом заключается в том, как в этой ситуации избежать диверсификации научного потенциала. «Дисциплинарный эклектизм, - размышляет П. Штомпка, - позволяет пересекать межтеоретические, а также междисциплинарные границы, возвращаясь к «социальной теории», как ее практиковали классики, - в противоположность узко заданной «социологической теории»» ${ }^{19}$. Междисциплинарность выводит науки - и гуманитарные, и собственно социальные - на рубежи тотальной соииальности, которая в качестве генеральной линии «схватывания» любого феномена или явления устанавливает систему координат общество - общество - общество, а не «общество - культура - человек» как более приемлемое для социологии сочетание.

Социальная теория, действительно, в отличие от социологических построений позволяет взглянуть на мир настолько широко, насколько это невозможно для самой социологии, тяготеющей к методической основательности и, значит, особое внимание уделяющей эмпирическому аппарату исследования. Вместе с тем социальная теория - это теория, построенная на междисциплинарном уровне; при таком положении дел участие различных наук в «социальном теоретизировании» как будто скрадывается. Это обстоятельство подтверждается нередким расхождением наук по бастионам прикладного знания либо теоретического.

\footnotetext{
${ }^{18}$ Кемеров В.Е. Гуманитарное и социальное: от оппозиции к синтезу // Человек. 2011. № 1. С. 15.

${ }^{19}$ Штомпка П. Формирование социологического воображения. Значение теории // Социол. исследования. 2005. № 10. C. 71 .
}

В том случае когда из культурологии, к примеру, вырастает прикладная культурология, из лингвистики прикладная лингвистика и т. д. (и, кстати, прикладная социология или эмпирическая социология как технологическая область социологической науки), а в свою очередь, некоторые дисциплины получают в довесок выраженный социальный уклон (социальная психология, социальная культурология и др.), тогда, повидимому, можно вести речь о некой растерянности наук перед всепроникающей междисциплинарностью. Для таких отраслей знания важный смысл приобретают именно целевые установки на получение новой информации в предельно конкретизированных сферах бытия человека и общества.

Итак, социология занимает особое место среди других наук; она передает интенции сощиильного другим научным областям, по сути, создавая водоворот междисциплинарного взаимодействия, в который втягиваются многие и многие познавательные системы; в то же время социология, утратив статус исключительно науки об обществе и зафиксировав в качестве своего объектно-предметного мира отношения общества, культуры и человека, включается в междисциплинарные проекты современных гуманитарных и социальных наук. В этих условиях важно и для социологической науки, и для любой другой соответствовать известным принципам научности и не утратить важнейшей гносеологической функции.

\section{Библиография:}

1. Александров Ю.И., Кирдина С.Г. Типы ментальности и институциональные матрицы: мультидисциплинарный подход // Социол. исследования. 2012. № 8 .

2. Александровский Ю.А. Социальные катаклизмы и психическое здоровье // Социол. исследования. 2010. № 4.

3. Алексеева И.Ю. Модели философии // Философские науки. 2012. № 9.

4. Ахиезер А.С. Об особенностях современного философствования (Взгляд из России) // Вопросы философии. 1998. № 2.

5. Беньямин В. Произведение искусства в эпоху его технической воспроизводимости. М., 1996.

6. Гудков Л.Д. Социология культуры: научно-аналитический обзор тематического номера «Кельнского журнала по социологии и социальной пси- 
хологии» // Культурология: Дайджест. М., 2012. № 1 (60).

7. Ельчанинов В.А. Негативная методология науки: монография. Барнаул, 2012.

8. Кемеров В.Е. Гуманитарное и социальное: от оппозиции к синтезу // Человек. 2011. № 1.

9. Краснов М.А., Краснов П.М. К разработке Индекса охраны человеческого достоинства // Общественные науки и современность. 2011. № 6.

10. Култыгин В.П. Тенденции в европейской социологической теории начала XXI века // Социол. исследования. 2001. № 8.

11. Кутырев В.А. От какого наследства мы не отказываемся // Человек. 2005. № 2.

12. Лосев А.Ф. Страсть к диалектике. М., 1990.

13. Марков Б.В. Образ человека в постантропологическую эпоху // Вопросы философии. 2011. № 2.

14. Москвичев Л.Н. Этапы институционализации российской социологии // Социол. исследования. 2006. № 7.

15. Попов Е.А. Диверсификация социогуманитарного знания: смыслы социального и апология суперсоциального // Социол. исследования. 2012. № 11.

16. Соколов А.В. Формула интеллигентности // Вопросы философии. 2005. № 5.

17. Штомпка П. Формирование социологического воображения. Значение теории // Социол. исследования. 2005. № 10.

18. Щербина В.В. Существует ли сегодня наука социология? // Социол. исследования. 2012. № 8.

19. Эпштейн М.Н. Конструктивный потенциал гуманитарных наук: могут ли они изменять то, что изучают? // Философские науки. 2008. № 12.

\section{References (transliteration):}

1. Aleksandrov Yu.I., Kirdina S.G. Tipy mental'nosti i institutsional'nye matritsy: mul'tidistsiplinarnyy podkhod // Sotsiol. issledovaniya. 2012. № 8.

2. Aleksandrovskiy Yu.A. Sotsial'nye kataklizmy i psikhicheskoe zdorov’e // Sotsiol. issledovaniya. 2010. № 4.
3. Alekseeva I.Yu. Modeli filosofii // Filosofskie nauki. 2012. № 9.

4. Akhiezer A.S. Ob osobennostyakh sovremennogo filosofstvovaniya (Vzglyad iz Rossii) // Voprosy filosofii. 1998. № 2 .

5. Ben’yamin V. Proizvedenie iskusstva v epokhu ego tekhnicheskoy vosproizvodimosti. M., 1996.

6. Gudkov L.D. Sotsiologiya kul'tury: nauchno-analiticheskiy obzor tematicheskogo nomera «Kel'nskogo zhurnala po sotsiologii i sotsial'noy psikhologii»// Kul’turologiya: Daydzhest. M., 2012. № 1 (60).

7. El'chaninov V.A. Negativnaya metodologiya nauki: monografiya. Barnaul, 2012.

8. Kemerov V.E. Gumanitarnoe i sotsial'noe: ot oppozitsii k sintezu // Chelovek. 2011. № 1.

9. Krasnov M.A., Krasnov P.M. K razrabotke Indeksa okhrany chelovecheskogo dostoinstva // Obshchestvennye nauki i sovremennost’. 2011. № 6.

10. Kultygin V.P. Tendentsii v evropeyskoy sotsiologicheskoy teorii nachala KhKhI veka // Sotsiol. issledovaniya. 2001. № 8.

11. Kutyrev V.A. Ot kakogo nasledstva my ne otkazyvaemsya // Chelovek. 2005. № 2.

12. Losev A.F. Strast' k dialektike. M., 1990.

13. Markov B.V. Obraz cheloveka v postantropologicheskuyu epokhu // Voprosy filosofii. 2011. № 2.

14. Moskvichev L.N. Etapy institutsionalizatsii rossiyskoy sotsiologii // Sotsiol. issledovaniya. 2006. № 7.

15. Popov E.A. Diversifikatsiya sotsiogumanitarnogo znaniya: smysly sotsial'nogo i apologiya supersotsial'nogo // Sotsiol. issledovaniya. 2012. № 11.

16. Sokolov A.V. Formula intelligentnosti // Voprosy filosofii. 2005. № 5.

17. Shtompka P. Formirovanie sotsiologicheskogo voobrazheniya. Znachenie teorii // Sotsiol. issledovaniya. 2005. № 10 .

18. Shcherbina V.V. Sushchestvuet li segodnya nauka sotsiologiya? // Sotsiol. issledovaniya. 2012. № 8.

19. Epshteyn M.N. Konstruktivnyy potentsial gumanitarnykh nauk: mogut li oni izmenyat' to, chto izuchayut? // Filosofskie nauki. 2008. № 12. 